\title{
The Experimental Behavior of the CFST Column and Beam Externally Bonded by CFRP Strips
}

\author{
Beerinder Singh ${ }^{1}$, Suneha Dhiman ${ }^{2, *}$ \\ ${ }^{1}$ Department Student of Civil Engineering, Chandigarh University, Mohali, Punjab, India \\ ${ }^{2}$ Department of Civil Engineering, Chandigarh University, Mohali, Punjab, India
}

Received February 3, 2021; Revised March 31, 2021; Accepted April 18, 2021

\begin{abstract}
Cite This Paper in the following Citation Styles
(a): [1] Beerinder Singh, Suneha Dhiman, "The Experimental Behavior of the CFST Column and Beam Externally Bonded by CFRP Strips," Civil Engineering and Architecture, Vol. 9, No. 3, pp. 656-669, 2021. DOI: 10.13189/cea.2021.090309.
\end{abstract}

(b): Beerinder Singh, Suneha Dhiman (2021). The Experimental Behavior of the CFST Column and Beam Externally Bonded by CFRP Strips. Civil Engineering and Architecture, 9(3), 656-669. DOI: 10.13189/cea.2021.090309.

Copyright $(2021$ by authors, all rights reserved. Authors agree that this article remains permanently open access under the terms of the Creative Commons Attribution License 4.0 International License

\begin{abstract}
This research article has been analyzed to examine the structural enhancement of concrete-filled steel tube (CFST) sections used externally with carbon fiber reinforced polymer. Due to their structural benefits, concrete-filled steel tubular sections are among the most common today. High strength, reduced cross-section, excellent seismic-resistant structural properties, increased fire resistance, and improved visible stiffness are just some of the advantages. Carbon fiber was used as a form of strips with a different number of layers and strip spacing on beam and column specimens. Twelve columns were tested, ten of which were externally reinforced with CFRP strips of various widths and spacing, and the remaining two columns were not reinforced with carbon fiber. However, ten beams were tested, eight of which were externally reinforced with CFRP strips of various widths and spacing, and the other two beams were not reinforced with carbon fiber. All specimens were tested at one point loading under a universal testing machine. Experimental results found that in comparison to the reference column and beam, the CFST column and beam specimens reinforced by carbon fiber have a higher load capacity.
\end{abstract}

Keywords CFST, CFRP, Flexural Strengthening, Axial Strengthening

\section{Introduction}

CFRP fabrics have been used in steel wrapping systems of columns. Parallel wrapping of CFST columns is one of the most effective and widely used CFRP strengthening methods since it has been observed to enhance both the stiffness of column specimens and their axial load-bearing capability. The main variable single types of FRP features are used in this paper with a rigid mild steel tube. Fiber-reinforced polymer strips were used as flat attachments, with several other requirements such as various numbers of layers, the width of the strip, and spacing of carbon fiber.

The combination of carbon fiber and concrete-filled steel tubular square systems has been investigated. It's a simple and cheap method for increasing the load-carrying capability of a structure. During flexural testing, the outside covering of CFRP fabrics under high load conditions indicates a greater increase in moment carrying ability and reduced deflection in beams. Carbon fiber composites use it as well, and it has certain advantages, such as irregular surfaces or connecting to curves, as well as elasticity to adapt in the right way for strength. Its purpose is to create a variety of wrapping methods that can be utilized to repair structures, as well as to examining the impact of increasing the number of FRP layers in increasing moment carrying capacity.

Laminate strips consisting of carbon fiber material are used to strengthen columns and beams. The outer portion of CFST individuals is laminated with CFRP. CFRP is also used for concrete, steel, and metal frame restoration and reconstruction. It's easy to put together and check immediately. Furthermore, they are eco-friendly and have 
a high modulus.

Concrete-filled steel sections have been widely used because they are critical for the overall structure's safety. Steel tubes are loaded with concrete in a structural portion known as CFST. Since the CFST section can have greater load capacity, they are used in bridges and high-rise buildings. Under outer load, the external CFST tube and internal concrete work together. The use of CFST beams and columns is critical for achieving quality work. By mixing steel tube and concrete, CFST sections offer the perfect combination. There are several benefits of the CFST structure such as stiffness; stable ductility, high load absorption capacity, and fire resistance.

\section{Literature Review}

Shams and Saadeghvaziri[1] described the impact of the concrete-filled steel column specimens as well as theoretical and experimental performance. On the effectiveness of CFT members, the key requirements of columns were cross-sectional structure, measurements, and column length. 286 column specimens were examined under concentric axial loads in this article. For research, six sizes of CFT columns in three different shapes were used, including circular, rectangular, and octagonal shaped steel tubes with a range of wall thicknesses. In two locations, the CFT column failed. Firstly due to buckling, and then concrete crushing.

Varma, et al.[2] The behavior of CFST members with a square shape was studied in this paper. The research measured eight CFST beam-column specimens. Axial and flexural compression machines were used to measure all specimens of CFST columns and beams. The CFST column and beam members were both 4.0 meters long. According to this research, the ductility curves of the CFST beam-column decrease dramatically as the $b / t$ ratio of the concrete-filled steel tube increases.

Mursi and $\mathrm{Uy}[3]$ the experimental behavior of large and small buckling of the CFST box column section was investigated. The entire buckling capability of the CFST specimens was tested three times. The plate slenderness of these CFST columns is $36.0,46.4$, and 56.8. All of the steel sections were constructed from a steel plate with a $3 \mathrm{~mm}$ wall thickness. This paper also investigated the deflection and stress-strain of all column specimens. The analysis shows the maximum load-deflection response of all columns during peak load.

Liu and Gho[4] presented the behavior of CFST rectangular stub column structures subjected to axial loading was tested and investigated. In this research, twenty-six samples were placed through their angles on an axial compression machine with a load capacity of $5000 \mathrm{KN}$. During the testing of column specimens, all specimens showed the best ductility results.

Gautam and Matsumoto[5] experimental failure modes of carbon fiber reinforced polymer box beams wrapped in unfilled and CFST wrapping. Twenty small beams were presented in this work, with five types of CFRP used for the CFST section, and measured in a four-point loading under the axial and flexural machine. The failure process was also tested using finite element analysis. Fractures in the concrete of the CFST beam were found early during tests. Mostly concrete-filled steel tube beam members cracked at $35 \%$ to $55 \%$ of loading, and it increased gradually in levels and percentage.

Kim, et al.[6] presented the response of CFST columns used with carbon fiber fabrics was presented. Axial compression machines have been constructed out of CFRP reinforced columns with no diagonal and horizontal steel members. On a larger scale, specimens such as diameter of $300 \mathrm{~mm}$ and $600 \mathrm{~mm}$ long rounded columns bound by carbon fiber with different layers and shapes were established. Circular steel tubes with various CFRP wrapping directions have been used in this research. In contrast to unwrapped steel tubes, the axial stress-strain performance and load-carrying capacity were higher.

Sundarraja and Prabhu[7] under the flexural loading test; carbon fiber was used to reinforce the CFST beams on the outside. This research evaluated a total of eighteen beams, nine of which were strengthened with full-wrapping and nine of which were reinforced with U-wrapping. The impact of different estimates of carbon fiber layers on the ability and stiffness of the member was studied. It shows that as the number of layers was rised, the ductility of the reinforced beams was reduced, which caused the quick fracture.

$\mathrm{Yu}, \mathrm{Hu}$ and Teng[8] the behavior of carbon fiber polymer coated in circular steel columns and evaluated on cyclic axial loading was introduced and examined. The essential contribution of this study is to look at the CFST column's external buckling; two series of axial compression were examined and introduced. This implemented the seismic effects' axial stress-strain efficiency of the CFT modeling.

Kiruthika, et al.[9] under an axial compression machine, evaluate the strength of carbon fiber polymer limited by slender rounded steel columns. CFRP wraps were used in samples of different sizes, including diameter, width, and height. A total of six columns are used in the article, with various strip widths and spacing. The load capacity of CFST reinforced with carbon fiber was measured in failure mode with axial loading and lateral deformation. It was found that the spacing and number of layers of CFRP seemed to have a significant impact on the CFST columns' strength.

Alam, Fawzia and Liu[10] presented the analysis of cross-section effect loading on carbon fiber bond length strengthened CFST columns. In this article, the specific parameters are analyzed: impact on carbon fiber density, velocity, modulus, and axial static loading of reinforced members. The optimal wrapping method was used to 
improve the CFST column in this article. By effectively avoiding buckling of the CFST members, it has an impact on transverse loading and axial static loading.

Shankar, et al.[11] presented the behavior of reinforced CFRP strips on the outside is a promising method to controlling axial deformation and improving the peak load of members. According to findings, when the strips were bonded together, the deformation of the columns was reduced by 141.2 percent and 69.75 percent, respectively, as a comparison to the reference column when placed at a spacing of $20 \mathrm{~mm}$ and $40 \mathrm{~mm}$, and this procedure was used to rehabilitate and reinforce concrete-loaded steel tube specimens. The study showed that from the outside, connecting composite polymer strips is an important method for controlling axial deformation and increasing the ultimate strength of compression columns.

$\mathrm{Xu}$, Zou and $\mathrm{Fu}[12]$ the force transmitting scheme was used to prepare the performance of the CFRT column were presented. It maintains the internal concrete and outer steel tubes, which work together to increase CFRT members' efficiency. The findings indicated that agreed force transmission sections over the steel field would help the CFRT column to perform better.

Balamurugan and S[13] presented the carbon fiber reinforced polymer affected structural members in various orientations and coverage areas. Three laminate methods with two types of fibers, CFRP and GFRP were used to stabilize the RC slabs. The structures are divided into three categories based on the orientation of the FRP sheets: corner, middle, and side wrapping. There are 3 different ratios of FRP coverage area in each device, varying from $25 \%$ to $35 \%$ to $45 \%$. Fifty-four slabs were designed and tested for each version at a rate of 3 samples for each variant. The outcomes indicated that as compared to the control slab, the middle wrapping has the most ductility.

\section{Methods of Materials}

\subsection{Concrete}

In this research, the mix design for the M25 concrete grade was presented. The concrete grade M25 has a 1:1:2 ratio. We used a 0.45 water-cement ratio and cast three concrete cubes for 28 days, as shown in (Figure 1). The concrete cube is $150 \times 150 \times 150 \mathrm{~mm}$ in dimension. As seen in, the cube's average compressive strength is $32.3 \mathrm{~N} / \mathrm{mm}^{2}$, as shown in (Table 1).

Table 1. Concrete cube's value

\begin{tabular}{|c|c|c|}
\hline Cube size & $\begin{array}{c}\text { Number of } \\
\text { Specimens }\end{array}$ & $\begin{array}{c}\text { Compressive } \\
\text { strength }\left(\mathbf{N} / \mathbf{m m}^{2}\right)\end{array}$ \\
\hline \multirow{3}{*}{$\begin{array}{c}150 \times 150 \times 150 \\
\mathrm{~mm}\end{array}$} & 1 & 32 \\
\cline { 2 - 3 } & 2 & 33 \\
\cline { 2 - 3 } & 3 & 32.1 \\
\cline { 2 - 3 } & Average & 32.3 \\
\hline
\end{tabular}

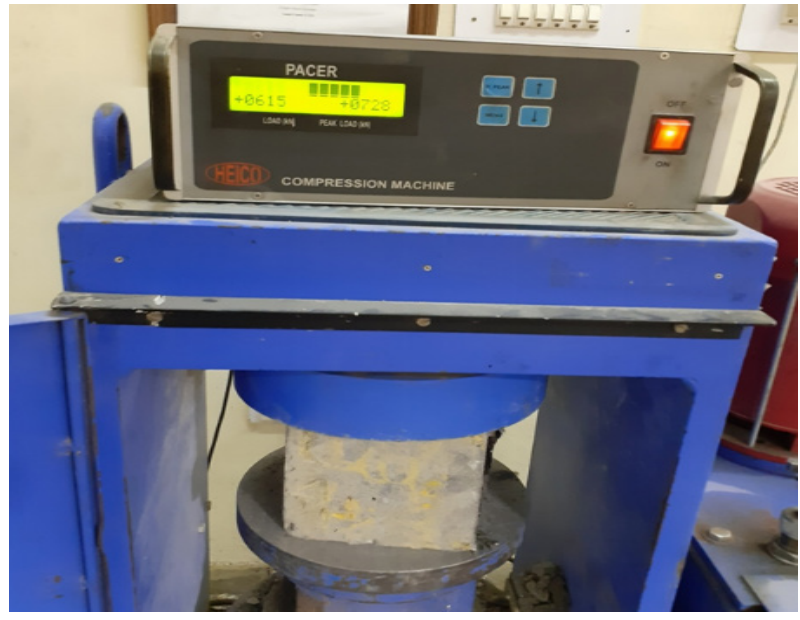

Figure 1. Compressive strength of concrete cube

\subsection{Concrete-Filled Steel Tube}

Indian standard code 4923-1997 applies to steel tubes. The steel tube specimen was $72.0 \times 72.0 \times 3.2 \mathrm{~mm}$ in size. The beam and column specimen lengths used were 1400 and $600 \mathrm{~mm}$, as seen in (Figure 2). The steel tube's yield stress was $240 \mathrm{~N} / \mathrm{mm}^{2}$.

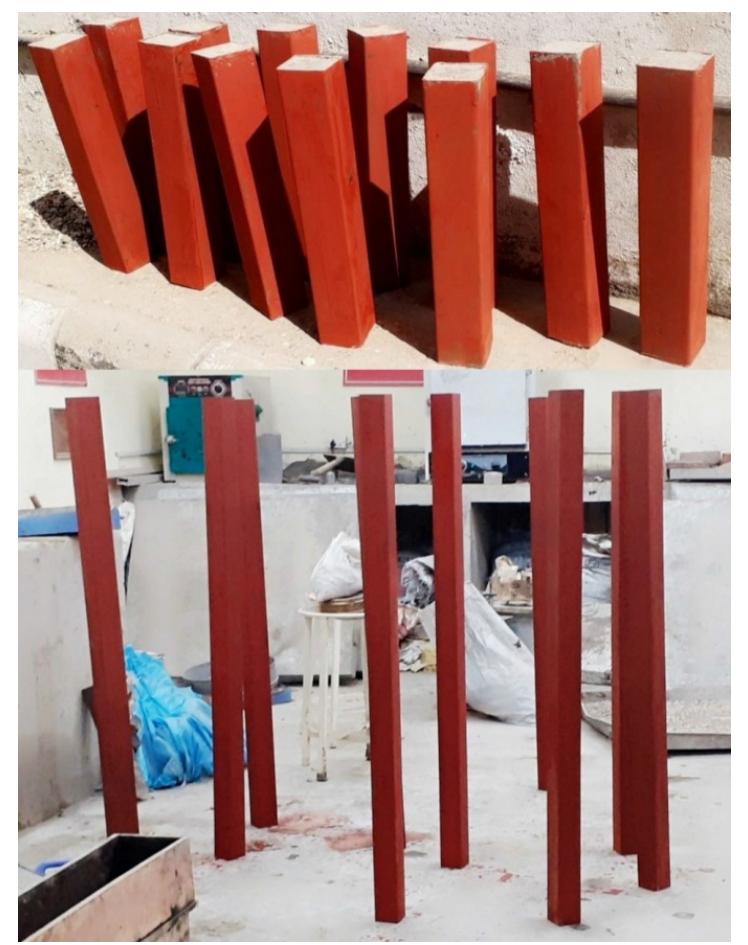

Figure 2. Steel tubes for columns and beams

\subsection{Carbon Fiber}

In this research study, carbon fiber was used as a strip. Its thickness and width are $0.123 \mathrm{~mm}$ and 500 , respectively. It is a low modulus fabric, as seen in (Figure 3). Carbon fiber has a tensile strength of $3500 \mathrm{~N} / \mathrm{mm}^{2}$ and elasticity modulus is $240 \mathrm{KN} / \mathrm{mm}^{2}$. 


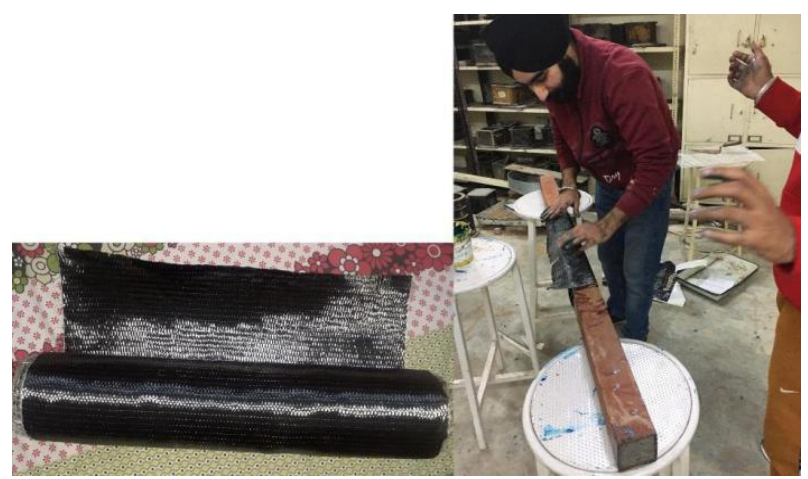

Figure 3. Carbon fiber reinforced polymer

\subsection{Adhesive}

This research used Araldite Epoxy adhesive, which is a multipurpose epoxy adhesive. It is compatible with composites, metal, concrete, and plastics. It's used to join carbon fiber and steel tubes together. This adhesive is simple to use and has strong holding power. It also has fast curing systems and low temperatures. The resin and hardener are mixed together at a ratio of $1: 1$, which is shown in (Figure 4).

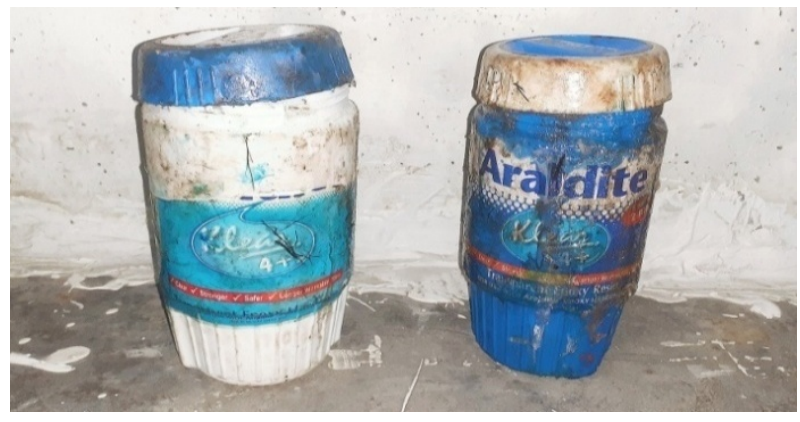

Figure 4.Araldite epoxy resin

\section{Experiment Analysis for Flexural Strengthening}

The purpose of this research is to investigate the suitability of concrete-filled steel tube beams using carbon fiber with the help of Araldite epoxy resin under flexural loading in a universal testing machine.

\subsection{Sampling Technique of Beam Specimens}

Both ends of the steel tubes were hollow, and the beam specimen was flat and square-shaped. The beam specimens were cleaned with acetone, and the concrete was filled into steel tubes and compacted with a steel rod. To corrosion resistance, we used red oxide primer for 24 hours on all beam specimens. All specimens took place in a water curing tank for 28 days. After that, carbon fiber is used in all the beam specimens with the help of Araldite epoxy resin.

\subsection{Experimental Arrangement}

The CFST beam experiments were carried out at one point loading on a universal testing machine. This machine can hold a hundred tons of weight. All beam specimens were measured for fracture point, deflection, and percentage of load-carrying ability throughout this experiment. Each point load was observed in both the initial and failure stages.

\subsection{Details of Beam Specimens}

A total of eight beams, except two reference beams, were tested in a universal testing machine. All of the beams are $72.0 \times 72.0 \times 3.2 \mathrm{~mm}$ in size, with a length of $1400 \mathrm{~mm}$, which is shown in Figure 5. Carbon fiber was used to strengthen all eight specimens. Every eight beams were reinforced using various wrapping techniques such as partial-fullywrapping, fully wrapping, partially-U-wrapping, and central with both end side wrapping of specimens to signify such as PFW-L2, FW-L1, PUW-L1, CBES-L1, as shown in (Table 2). L1 is the total number of layers of carbon fiber. The term "reference beam" refers to a steel tube beam that has no carbon fiber strips bonded to it. One and two layers of carbon fiber strips were used to construct these beams.

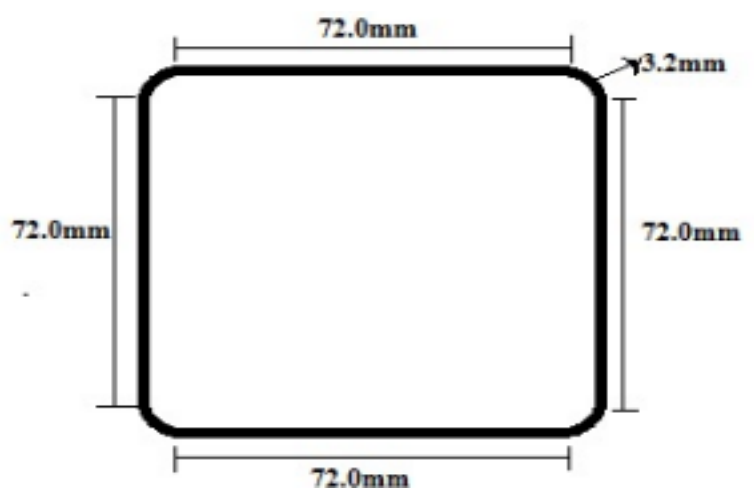

Figure 5. Front Size of steel tube

Table 2. Wrapping methods

\begin{tabular}{|c|c|}
\hline Shape of Wrapping methods & Number of layers \\
\hline Full-Wrapping & Layer 1 and 2 \\
\hline Partial-fully-Wrapping & Layer 1 and 2 \\
\hline Partial-U-Wrapping & Layer 1 and 2 \\
\hline $\begin{array}{c}\text { Center with both end sides } \\
\text { wrapping }\end{array}$ & Layer 1 and 2 \\
\hline
\end{tabular}

\section{Result and Discussions}

\subsection{Deflection Behavior and Failure Pattern of All Beam Specimens}

A large load-deflection curve was shown in the reference beam. RB specimens were tested in a universal testing machine at one point loading, as shown in the (Figure 6). 
As compared to all beam specimens, these beams have a weaker deflection control capability of $24.6 \mathrm{~mm}$. Furthermore, a wide bending curve happened in the absence of carbon fiber. The load and deflection curve for the reference beam are as shown in (Graph 1).

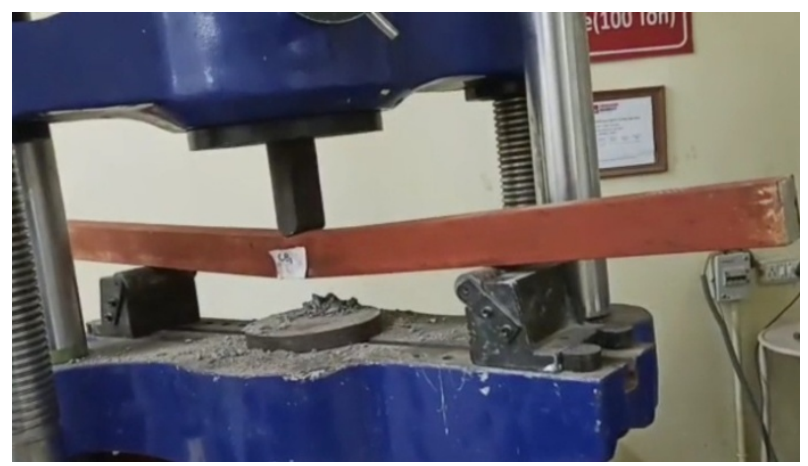

Figure 6.Failure mode reference beam

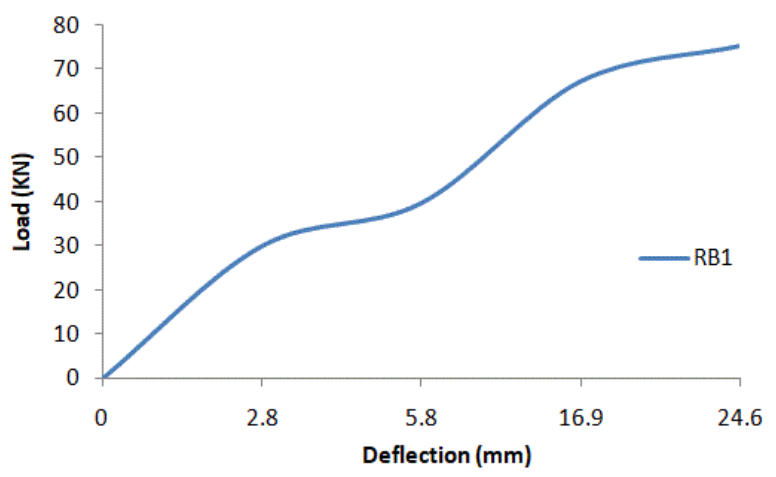

Graph 1. Load and deflection curve reference beam

In the beam of (full wrapped) layer one, minor crushing noise was noticed at the initial phase, due to the rupture of fiber. Furthermore, the beam was (full-wrapped) reinforced by one layer, which resulted in a $19.45 \mathrm{~mm}$ improvement in deflection control (Table 3) than the reference beam, but fewer deflection control in all wrapping methods beam members. Carbon fiber wrapping in two layers resulted in a $16.19 \mathrm{~mm}$ in rising in deflection control (Graph 2) as a comparison to the reference beam, which includes all wrapping methods (Figure 7)

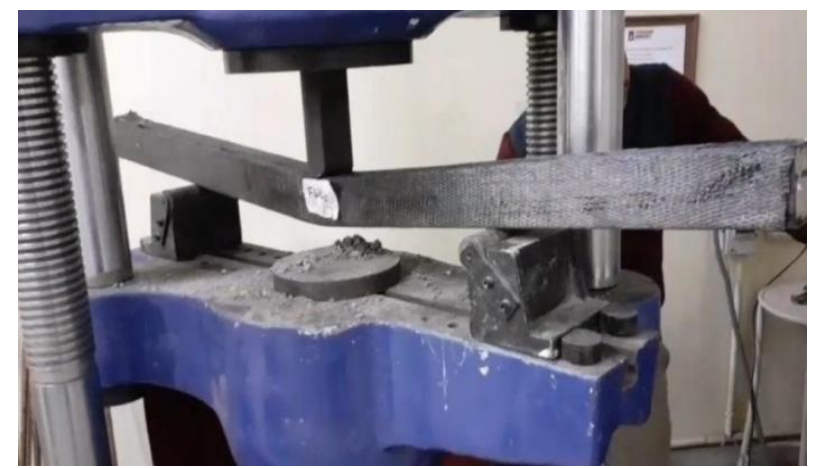

Figure 7. Failure mode FW-L2 beam

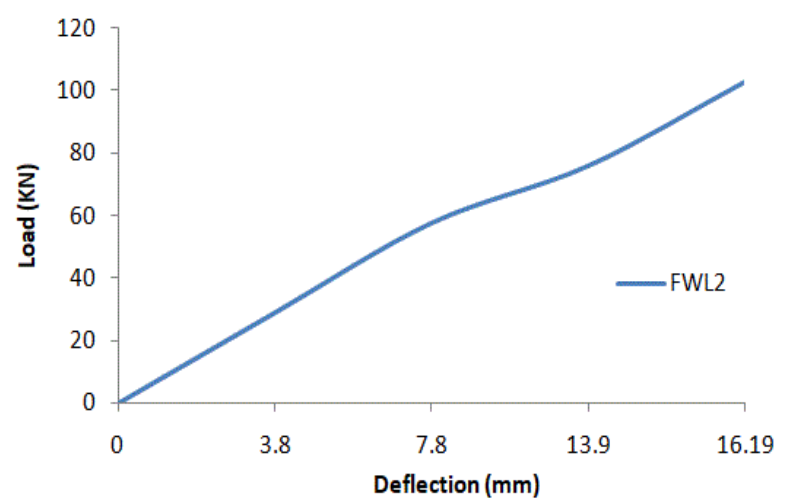

Graph 2. Load and deflection curve FW-L2 beam

In comparison to (fully-wrap) layer one, the partially-fully-wrapped beam reinforced by one layer shows an enhancement in deflection control, and the reference beam was around $17.23 \mathrm{~mm}$ as shown in (Table $3)$. In contrast, the beam is reinforced by two layers of the beam, which results in a slight fiber rupture (Figure 8) and a strong deflection control capacity of $14.95 \mathrm{~mm}$ as a comparison to other beam wrappings (Graph 3).

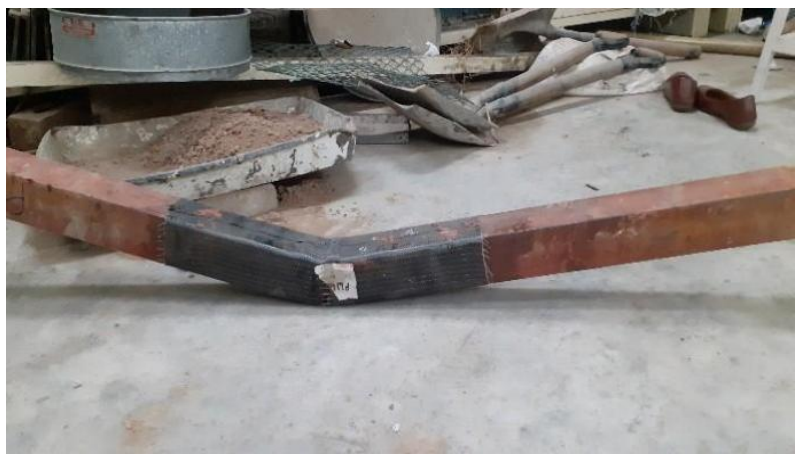

Figure 8. Failure mode PFW-L2 beam

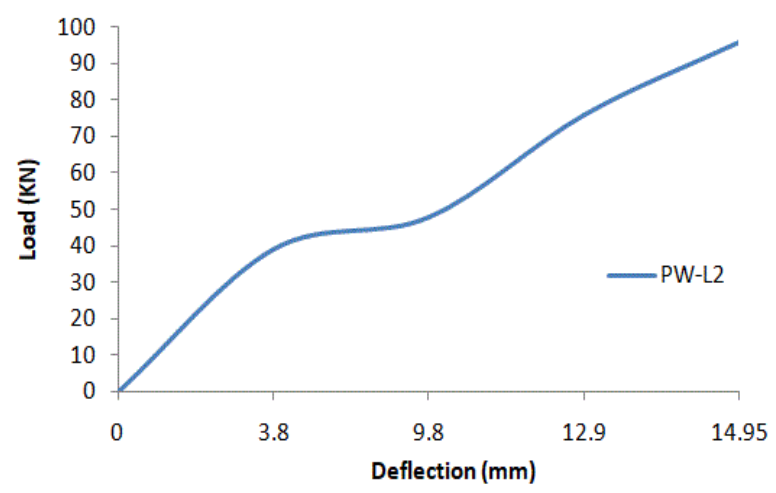

Graph 3. Load and deflection curve PFW-L2 beam

As compared to (reference beam) and (full-wrapped), immediate rupture on a beam of (Partial-U-wrapping) is used by one layer shows an improvement in deflection control of $18.89 \mathrm{~mm}$ at the initial stage of load, but low in a partial-full-wrapping of one layer. While the beam member is used by second layers of partially-U-wrapping, 
deflection control was enhanced at $16.73 \mathrm{~mm}$, as shown in the graph (Graph 4). In this two-layer specimen shown increased in deflection control ability in comparison to other beams, however not in a PFW of layer second and fully wrapping, as shown in (Figure 9).

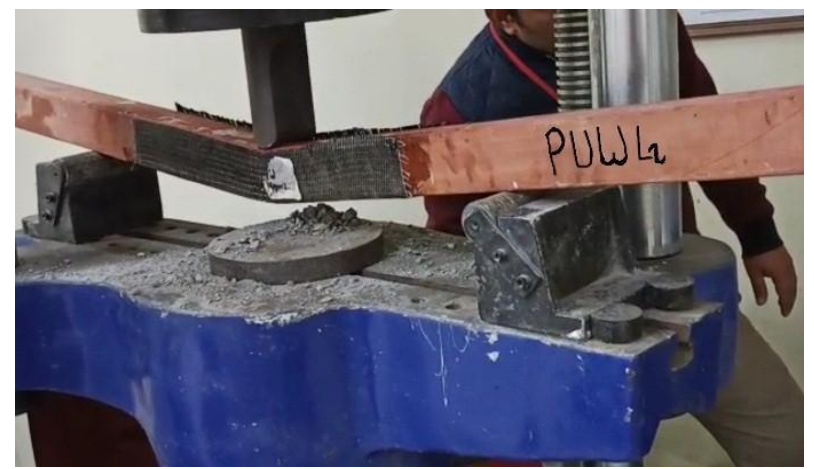

Figure 9. Failure pattern of PUW-L2 beam

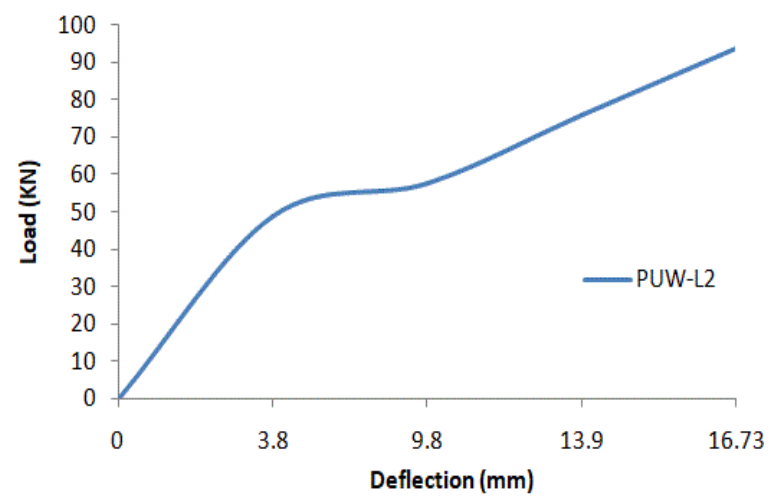

Graph 4. Load-Deflection curve of PUW-L2 beam

When a load is applied to a beam reinforced by (center with each end side wrapping), there is no carbon fiber fracture, as shown in (Figure 10). Fortunately, in comparison to all wrapping specimens except the reference beam, the first and second layers have lesser deflection control capacity of 20.47 and $21.78 \mathrm{~mm}$, which is shown in (Graph 5).

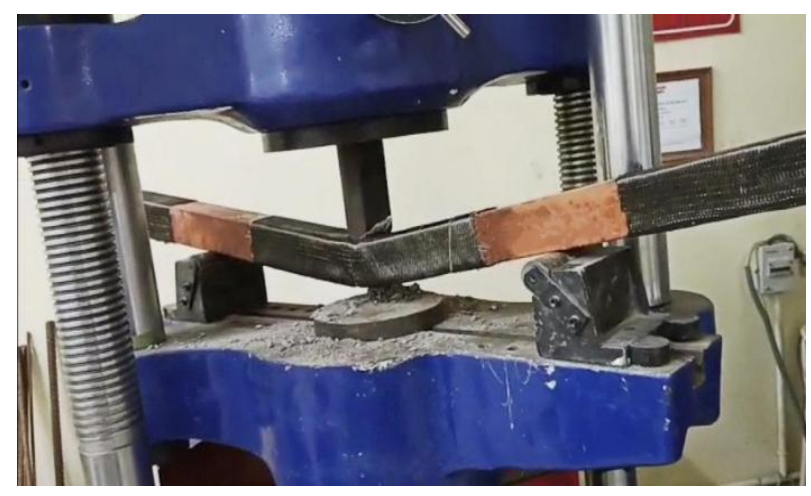

Figure 10. Failure pattern of CBES-L2 beam

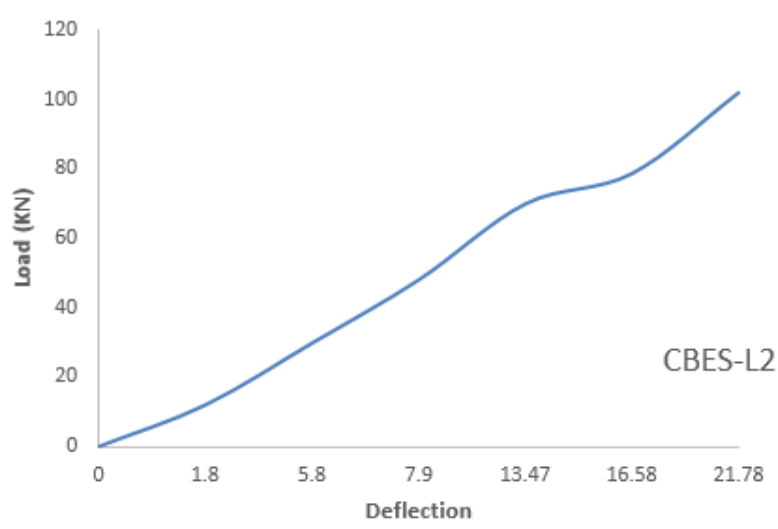

Graph 5. Load-Deflection curve of CBES-L2 beam

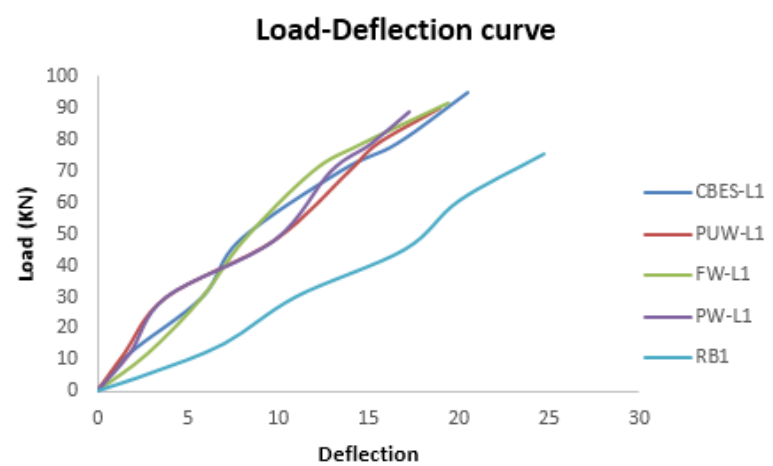

Graph 6. Load-deflection curves as comparison of reference beam and specimens of CFRP layer one

Graph 6 shows the comparison of load-deflection curves of all specimens of layer one with a reference beam. As it is clearly noticeable that RB1 has more deflection as compared to other beam specimens, as it was $24.67 \mathrm{KN}$. On the other hand, PW-L1 has a higher capacity to deal with a deflection as it can bear 17.23KN. Similarly, PUW-L1 and PW-L1 have almost the same deflection. 
Table 3. Peak load and behavior of deflection of all beam specimens

\begin{tabular}{|c|c|c|c|c|}
\hline $\begin{array}{c}\text { Details of } \\
\text { Specimens }\end{array}$ & $\begin{array}{c}\text { Peak load } \\
(\mathbf{K N})\end{array}$ & $\begin{array}{c}\text { Deflection } \\
(\mathbf{m m})\end{array}$ & $\begin{array}{c}\text { Percentage of increased load carrying capacity as compared } \\
\text { to reference beam-2 }\end{array}$ & $\begin{array}{c}\text { Fracture } \\
\text { load(KN) }\end{array}$ \\
\hline Reference beam-1 & 74.52 & 25.39 & - & - \\
\hline Reference beam-2 & 75.27 & 24.67 & - & - \\
\hline PFW-L1 & 88.76 & 17.23 & 17.9 & 81.00 \\
\hline PFW-L2 & 95.96 & 14.95 & 27.4 & 89.00 \\
\hline CBES-L1 & 94.69 & 20.47 & 25.8 & 87.00 \\
\hline CBES-L2 & 101.83 & 21.78 & 35.2 & 90.00 \\
\hline FW-L1 & 91.85 & 19.45 & 22.0 & 85.00 \\
\hline FW-L2 & 102.86 & 16.19 & 36.6 & 91.00 \\
\hline PUW-L1 & 89.91 & 18.89 & 19.4 & 83.00 \\
\hline PUW-L2 & 93.84 & 16.73 & 24.6 & 85.00 \\
\hline
\end{tabular}

\section{Load-Deflection curve}

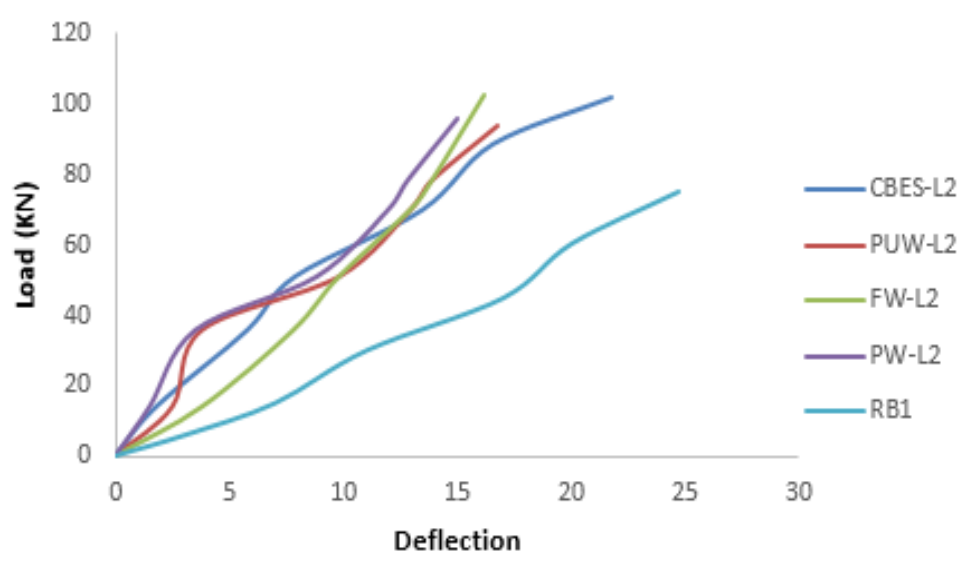

Graph 7. Load-deflection curves as comparison of reference beam and specimens of CFRP layer two

This Graph 7 represents the comparison of load-deflection curves of all specimens of layer two with the reference beam. Even in the case of Layer2, the Reference beam has maximum load deflection as compared to strengthened beams. Moreover, CBES-L2 has a load-deflection of $20.47 \mathrm{KN}$ and PUW-L2 has 18.8 , but PW-L2 has very low load deflection, it was about $14.95 \mathrm{KN}$.

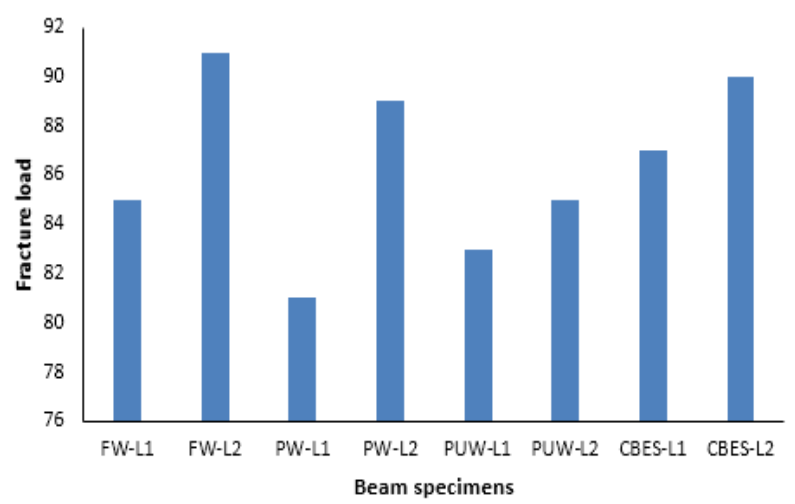

Graph 8. Relationship of fracture load and beam specimens
This Graph 8 shows the comparison of beam specimens and fracture load. It was noticeable that the FW-L2 specimen's maximum load was taken at $102.86 \mathrm{KN}$ after the fracture load of $91 \mathrm{KN}$ as compared to other beam specimens. However, in a specimen of FW-L1, the load reached fracture point at $85 \mathrm{KN}$. Then, fewer loads were taken in between fracture load and failure load. It was observed that the specimens which were strengthened by a single layer, the load suddenly decreased after the failure load of the specimen.

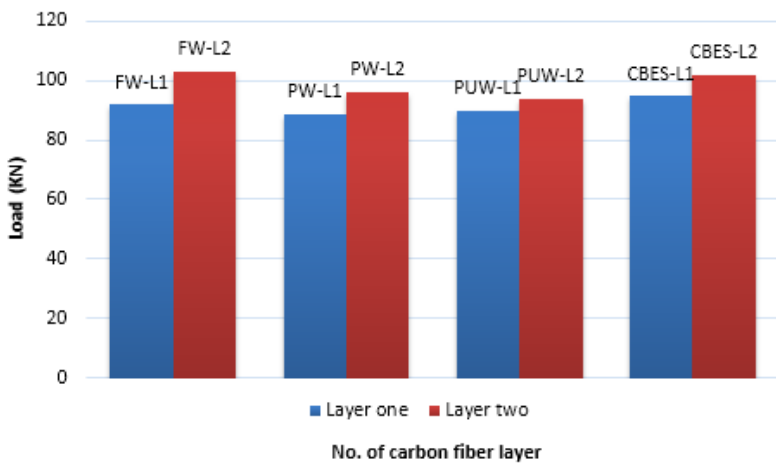

Graph 9. Comparison of Load and CFRP layers 
The contrast of loads and carbon fiber layers is represented in (Graph 9). Nevertheless, with a load of 102.86KN, FW-L2 has more load capacity than Fully-wrap one layer. Furthermore, PFW-L1 has a lower load capacity than PFW-L2, because partial-full-wrap layer two has higher load ability, as it resulted in $95.96 \mathrm{KN}$. However, CBES-L2 and FW-L2 have roughly similar load capacity. The CBES of layer two was $101.83 \mathrm{KN}$, and as (FW-L2) was $102.86 \mathrm{KN}$ as shown in (Table 3 ).

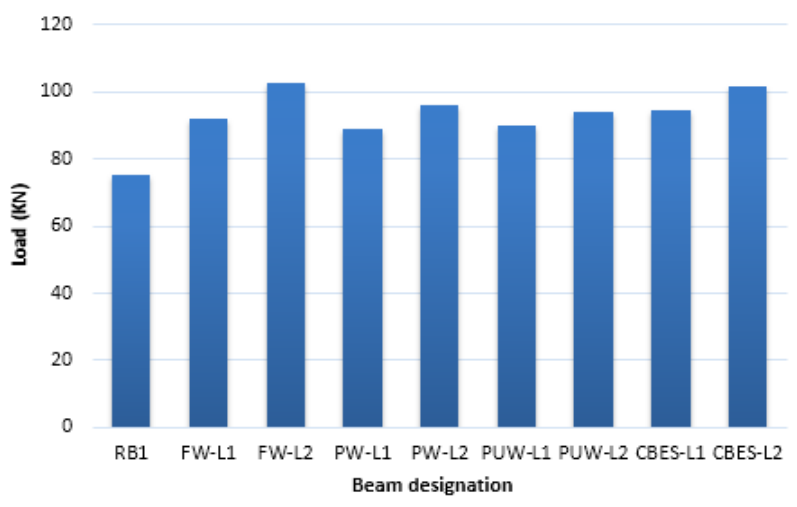

Graph 10. Comparison of Load and beam specimens

The impact of load and beam specimens is shown in (Graph 10). This graph shows that Full-Wrap-L2 has the highest load potential of all the beam members. Furthermore, as compared to CBES-L2, Full-Wrap-L2 has almost the same load capacity as Full-Wrap-L2, at $101.83 \mathrm{KN}$. The reference beam, on the other hand, has a very weak load-carrying capability compared to all other beam members, with a load-carrying capacity of $75.27 \mathrm{KN}$, which is shown in (Table 3).

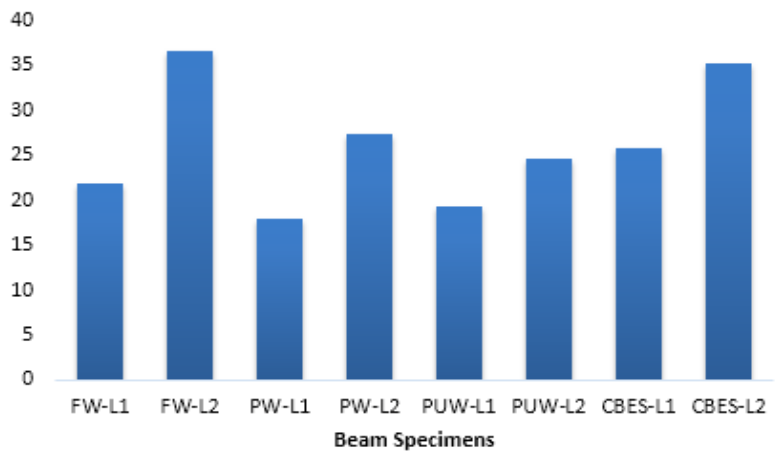

Graph 11. Comparison of \% of rise load carrying capacity with reference beam

In comparison to reference beams, this graph shows the percentage of increased load-carrying capacity. The proportion of Full-Wrap-L2 has a high load-bearing potential in contrast to the reference beam, at $36.6 \%$, and the CBES of the two layers, at $35.2 \%$, also had increased load-carrying capability. Three beam specimens were also capable of handling the load. PFW-L1, PUW-L1, and Full-Wrap-L1, and their values were $17.9 \%, 19.4 \%$, and $22.0 \%$, as shown in (Graph 11).

\section{Experiment Investigation for Axial Strengthening}

The purpose of this research is to analyze the suitability of concrete-filled steel tube columns using carbon fiber with the help of Araldite epoxy resin under axial loading in a universal testing machine.

\subsection{Sampling Technique of Column Specimens}

Both ends of the steel tubes were hollow, and the column specimen was flat and square-shaped. The column specimens were cleaned with acetone, and the concrete was filled into steel tubes and compacted with a steel rod. To corrosion resistance, we used red oxide primer for 24 hours on all column specimens. All specimens took place in a water curing tank for 28 days. After that, carbon fiber is used in all the column specimens with the help of Araldite epoxy resin.

\subsection{Experimental Arrangement}

The CFST column experiments were carried out at one point loading on a universal testing machine. This machine can hold a hundred tons of weight. All column specimens were measured for fracture point, deflection, and percentage of load-carrying ability throughout this experiment. Each point load was observed in both the initial and failure stages.

\subsection{Details of Column Specimens}

A total of ten columns, except two reference columns, were tested in a universal testing machine. All of the columns are $72.0 \times 72.0 \times 3.2 \mathrm{~mm}$ in size, with a length of $600 \mathrm{~mm}$. Carbon fiber was used to strengthen all ten specimens. Every ten columns were reinforced using various wrapping techniques such as, $40 \mathrm{~mm}$ width of carbon fiber, and spacing of carbon fiber $20,30,50,60 \mathrm{~mm}$, and full wrapping for every column specimen, as shown in (Figure 11) 

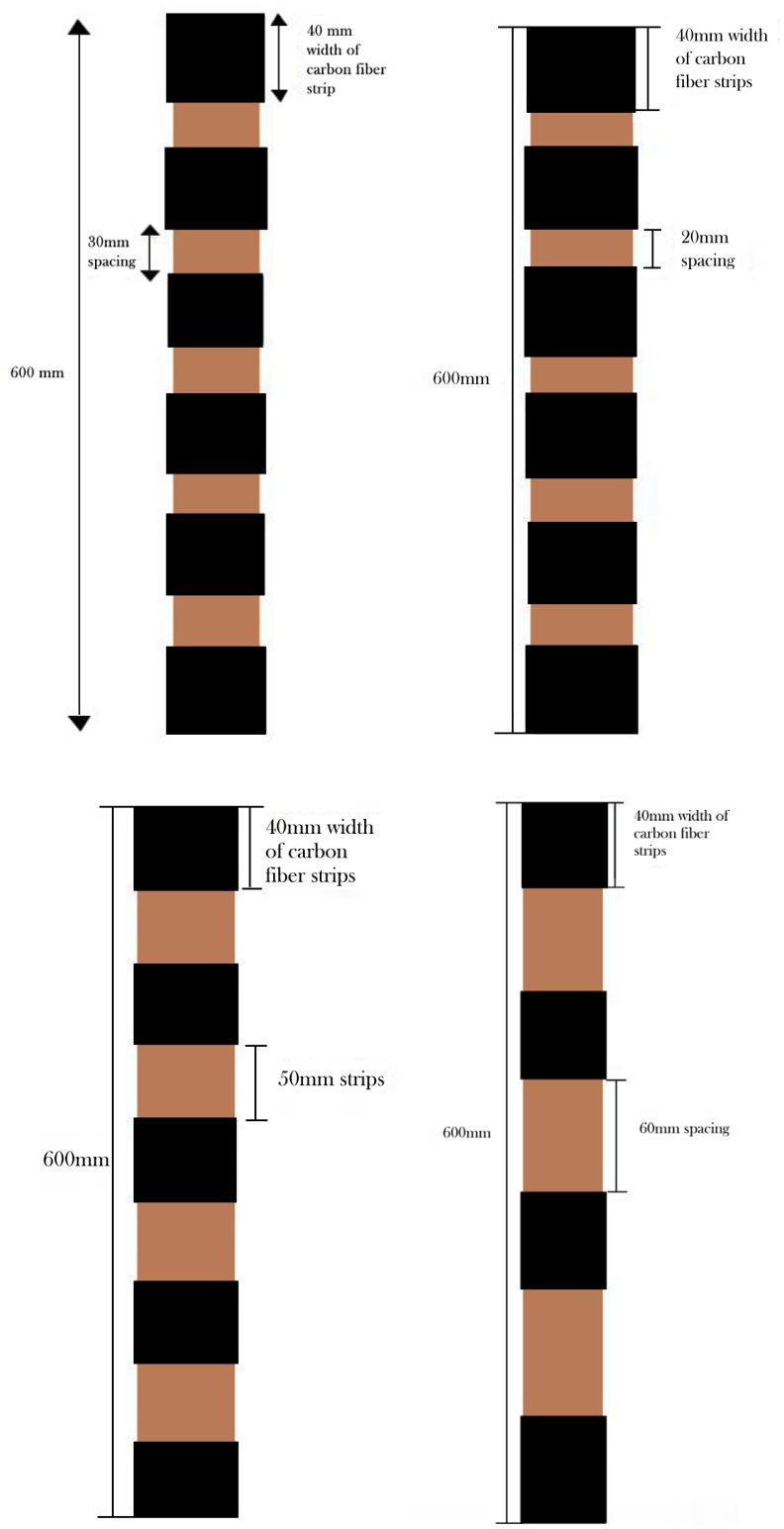

Figure 11. Wrapping method for columns

\section{Result and Discussions}

\subsection{Failure Pattern of All Column Specimens}

Due to external buckling on the lower edge, the CFST columns without carbon fiber bond failed. Slight concrete crack movements were noticed on both reference columns after the $400 \mathrm{KN}$ load reached, as shown in (Figure 12). In the reference column specimen, the peak load is at $450 \mathrm{KN}$, as shown in (Table 4).

The failure of the column specimen, which had a width of carbon fiber $40 \mathrm{~mm}$ and a spacing of $20 \mathrm{~mm}$, was observed at a load of $622 \mathrm{kN}$, as shown in (Table 4). Two layers of carbon fiber strengthen this specimen. In this column, no carbon fiber fracture has happened. This $20 \mathrm{~mm}$ carbon fiber spacing has a higher load-carrying performance and high control in deflection as compared to reference column and other wrapping methods, as shown in (Figure 12)

However, in the column specimen, carbon fiber used by one layer was fractured in the upper portion of the column. After that, external buckling and lower concrete crack were noticed. Consequently, the peak load was rapidly reduced. The maximum load occurred at $598 \mathrm{KN}$ in the UTM, as shown in (Figure 12).

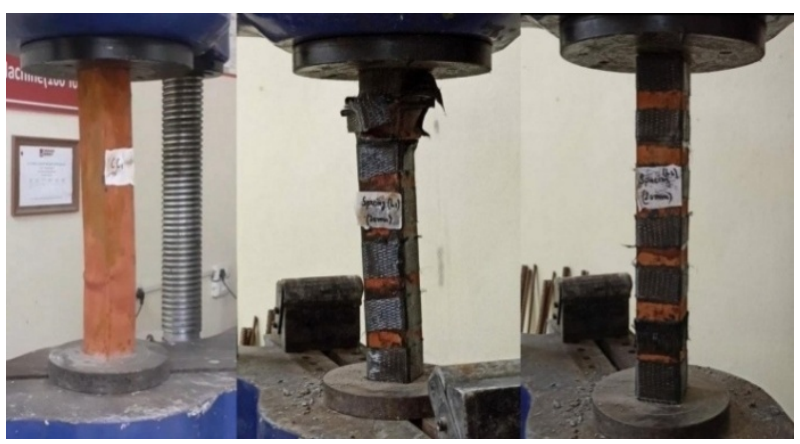

Figure 12. Failure modes RB, 20L1, and 20L2

A similar condition of column members, which had a spacing of CFRP $30 \mathrm{~mm}$ and width of CFRP $40 \mathrm{~mm}$, peak load of $580 \mathrm{kN}$, which is shown in (Table 4). One layer of carbon fiber was ruptured in the bottom edge column member. After that, outer buckling was in a CFST. Afterward, immediately the load is reduced in the UTM, which is shown in (Figure 13).

But the specimens bonded by two layers have not experienced any type of rupture in carbon fiber. The column has only a noticeable internal concrete cracking. In this case, the load-bearing ability of $30 \mathrm{~mm}$ spacing of carbon fiber reinforced by two layers is greater in comparison to reference column and other wrapping methods. The peak load on the column was $605 \mathrm{KN}$, as shown in (Table 4)

Full-wrapped carbon fiber failure occurred at a load of $595 \mathrm{kN}$. It used one layer of carbon fiber. In this column, a minor carbon fiber rupture occurred. The load immediately decreased after the internal concrete cracks were noticed. In comparison to the reference column, this column has a higher load-carrying capacity.

However, the column used by two layers of CFRP was fractured in the bottom position. The fractured of carbon fiber was experienced because of external buckling in the bottom position. Afterward, immediately the load was declined after the highest load of the column at $625 \mathrm{KN}$ in (Table 4) as compared to the reference column and other different wrapping specimens, which is shown in (Figure 13).

The specimen had 50mm spacing CFRP in both layers one and two occurred due to rupture of fiber at the upper position. It has shown low load carrying capacity and column specimen peak load at $589 \mathrm{kN}$ and $565 \mathrm{KN}$ in comparison to all other smaller spacing specimens and full-wrap, as shown in (Figure 13). 


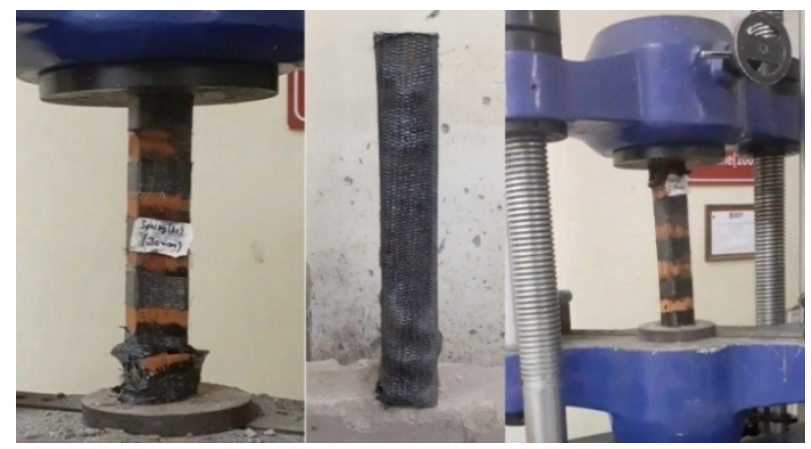

Figure 13. Failure modes 30L1, FWL2, and 50L1

The specimen has a carbon fiber spacing of $60 \mathrm{~mm}$ bonded by one layer which was caused by the separation of CFRP at the upper position because of the outer buckling of the column. It has shown lower load-bearing capacity at the point of failure load at $560 \mathrm{KN}$ in (Table 4 ) as compared to all other members, as seen in (Figure 14).

Similarly, specimens having carbon fiber spacing of $60 \mathrm{~mm}$ bonded by two layers caused a large separation of CFRP at the lower position in the column. It has shown the lower load-carrying capacity of load failure at $585 \mathrm{KN}$ as compared to all column specimens as shown in (Figure 14).

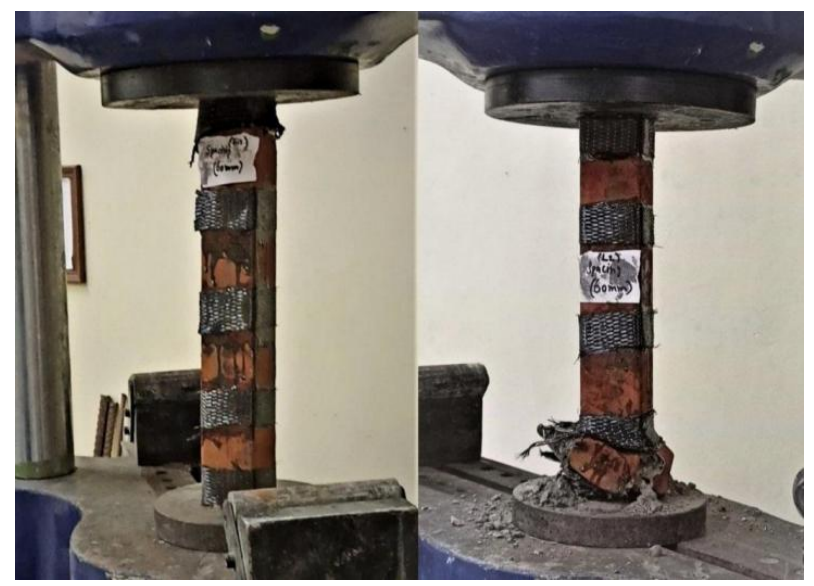

Figure 14. Failure modes 60L1, 60L2

\subsection{Axial Stress-Strain Behavior}

The axial stress-strain behavior of the un-wrapped column was found to have a stress of $60 \mathrm{~N} / \mathrm{mm} 2$, with a strain of 0.00029 . Moreover, while the load was in progress rising in the direction of upward, it achieved $86.8 \mathrm{~N} / \mathrm{mm} 2$. Then, immediately after attainment to peak load, it started to reduce load because of local buckling in the bottom edge is shown in (Graph 12).
The stress-strain curves of layers one and two were constantly increased at a $20 \mathrm{~mm}$ column spacing of carbon fiber. The strain was about 0.00058 at this time. But after, the reinforced column was also shown to have a flexible act. Preceded by an inflexible reaction as it started rising in the upward direction and reached the maximum point, with a slight curve in the graph at that point, as 115.3 and $119.9 \mathrm{~N} / \mathrm{mm}^{2}$, and then load immediately declined rapidly, as shown in (Graph 13, Graph 14).

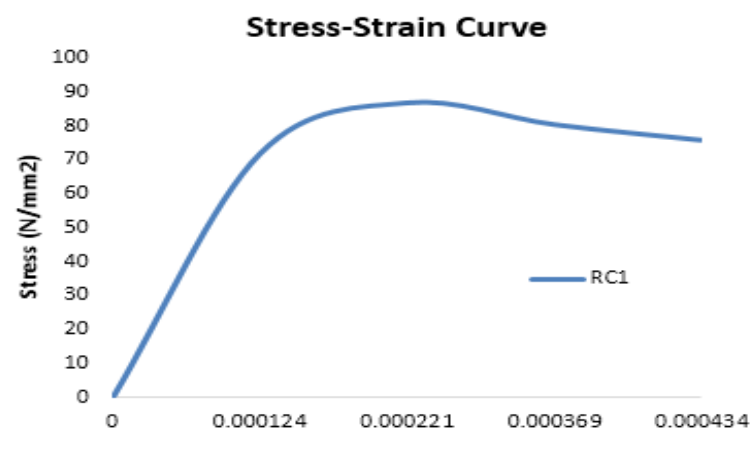

Graph 12. Stress-Strain of Reference column-2

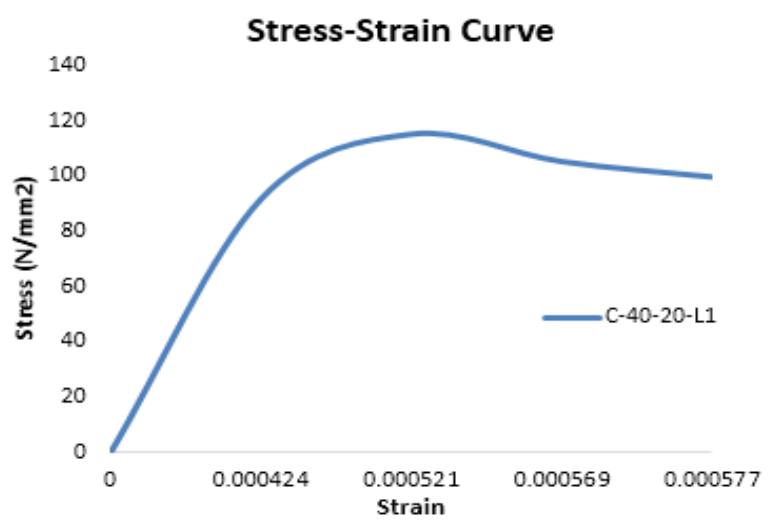

Graph 13. Stress-Strain behavior of $20 \mathrm{~mm}$ spacing

Likewise, at the point of maximum peak load, the stress-strain curve of $30 \mathrm{~mm}$ carbon fiber of layer one was increased. But after that, it began to fall in a circular motion because of carbon fiber breakup at the stress of $111.8 \mathrm{~N} / \mathrm{mm}^{2}$, as shown in the graph (Graph 15 ), exactly the same condition (Graph 16, Graph 17). When the load first started to increase, the peak load point immediately decreased. 


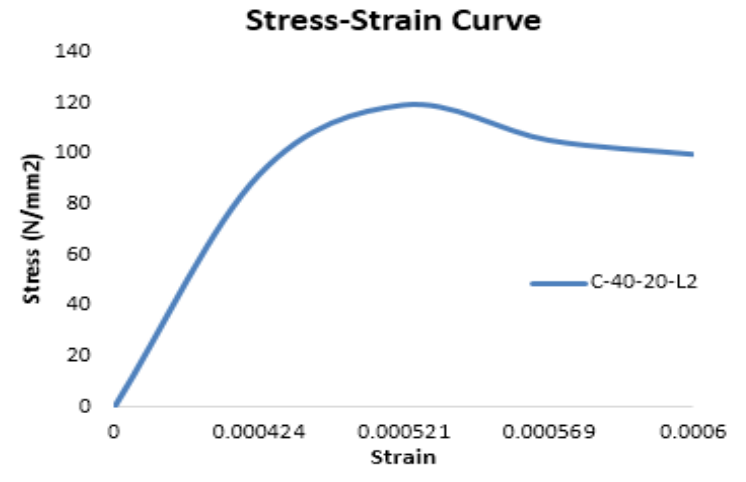

Graph 14. Stress-Strain of C-40-20-L2

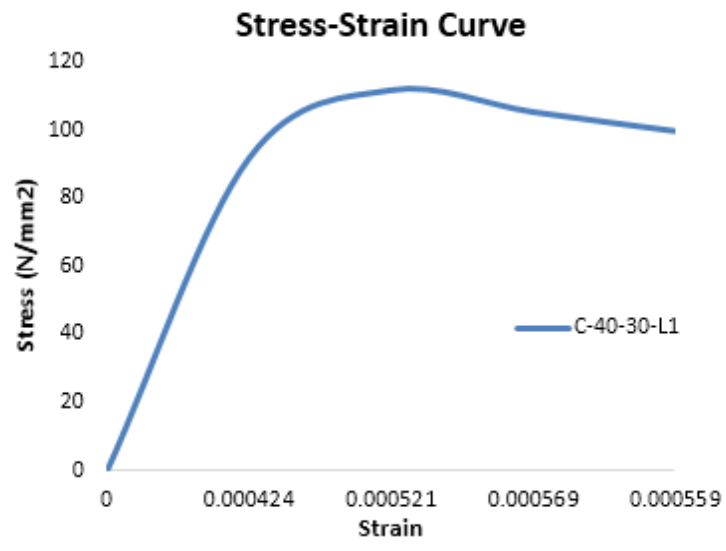

Graph 15. Stress-Strain behavior of $30 \mathrm{~mm}$ spacing

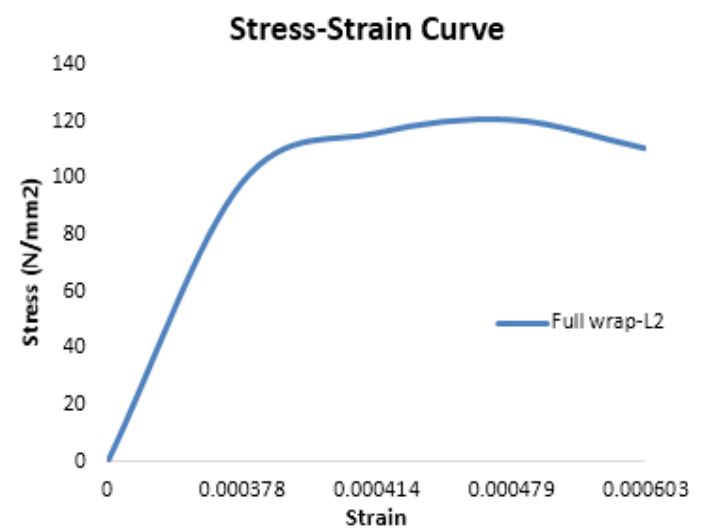

Graph 16. Stress-Strain of Full-Wrap-L2

Stress-Strain Curve

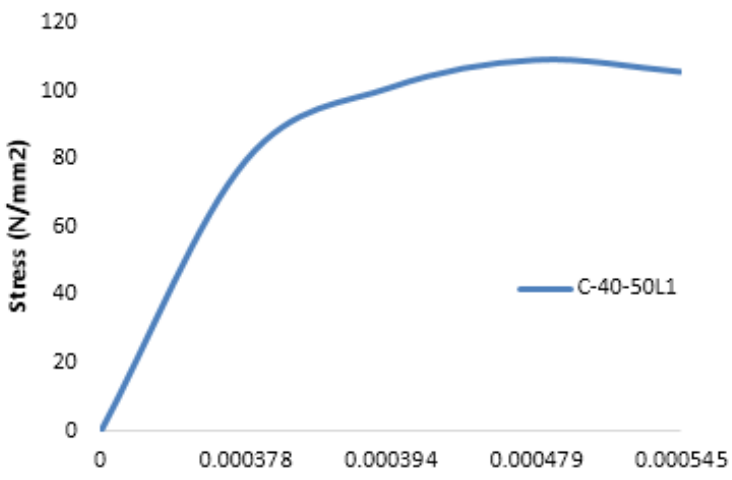

Graph 17. Stress-Strain of C-40-50-L1

Table 4. Peak load, Stress-Strain, and percentage of Load carrying capacity of all column specimens

\begin{tabular}{|c|c|c|c|c|c|}
\hline $\begin{array}{c}\text { Details of } \\
\text { specimen }\end{array}$ & $\begin{array}{c}\text { Peak Load } \\
\text { (KN) }\end{array}$ & $\begin{array}{c}\text { Fracture Load } \\
\text { (KN) }\end{array}$ & $\begin{array}{c}\text { Percentage of increased } \\
\text { load carrying capacity } \\
\text { Compared to Reference } \\
\text { column-2 }\end{array}$ & $\begin{array}{c}\text { Highest Stress } \\
\text { (N/mm } \mathbf{m}^{2}\end{array}$ & Highest Strain \\
\hline $\begin{array}{c}\text { Reference } \\
\text { column-1 }\end{array}$ & 432 & - & - & 83.3 & 0.0004165 \\
\hline $\begin{array}{c}\text { Reference } \\
\text { column-2 }\end{array}$ & 450 & - & 24.4 & 108.0 & 0.0004340 \\
\hline C-40-60L1 & 560 & 490 & 30.0 & 112.8 & 0.0005480 \\
\hline C-40-60L2 & 585 & 501 & 32.8 & 115.3 & 0.0005640 \\
\hline C-40-20L1 & 598 & 505 & 38.2 & 119.9 & 0.0005765 \\
\hline C-40-20L2 & 622 & 530 & 25.5 & 108.9 & 0.0005995 \\
\hline C-40-50L1 & 565 & 498 & 30.8 & 113.6 & 0.0005445 \\
\hline C-40-50L2 & 589 & 503 & 32.2 & 114.7 & 0.0005680 \\
\hline FW-L1 & 595 & 510 & 38.8 & 120.5 & 0.0005735 \\
\hline FW-L2 & 625 & 532 & 28.8 & 111.8 & 0.0006025 \\
\hline C-40-30L1 & 580 & 510 & 34.4 & 116.7 & 0.0005590 \\
\hline C-40-30L2 & 605 & 515 & & & 0.0005835 \\
\hline
\end{tabular}


Carbon fiber spacing of $60 \mathrm{~mm}$ improved the stress-strain performance of CFST members. At their peak load, both layers one and two were constantly growing. After that, surprisingly, there was a dramatic drop in the curve, but both curves of the stress-strain were similar, as seen in (Graph 18, Graph 19).

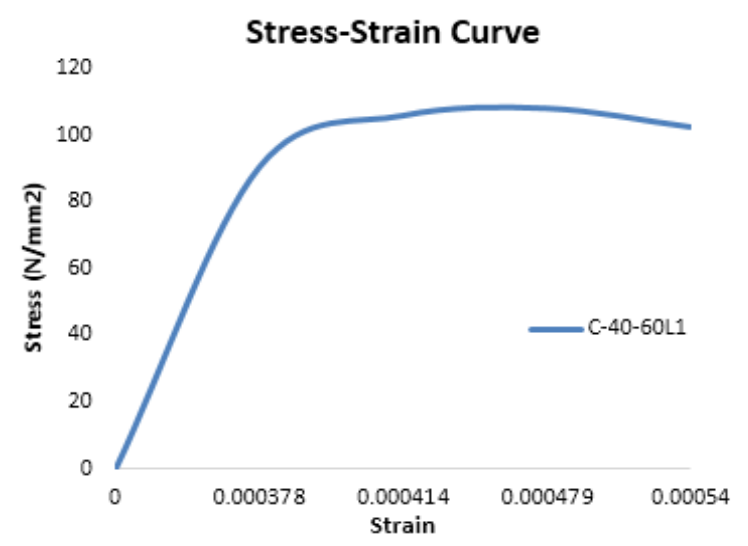

Graph 18. Stress-Strain of C-40-60-L1

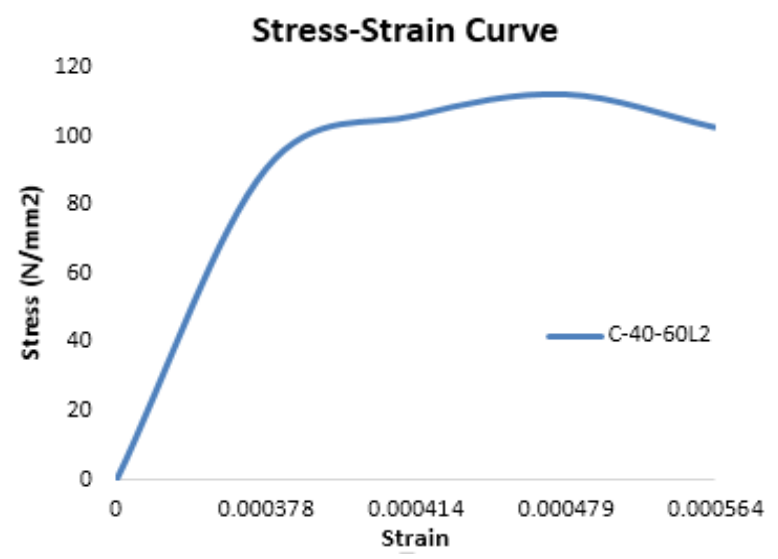

Graph 19. Stress-StrainofC-40-60-L2

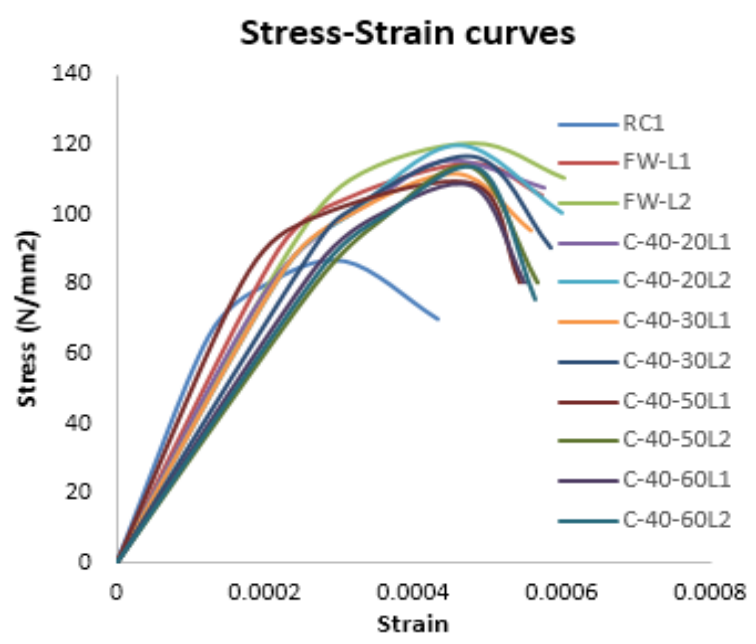

Graph 20. Stress-Strain curves for all column specimens

This graph illustrates the stress-strain curves of all column specimens. Although, $\mathrm{RC} 1$ has less stress of
$86.8 \mathrm{~N} / \mathrm{mm}^{2}$ and the strain was 0.0004340 . In comparison to all column specimens, FW-L2 has maximum stress and strain as compared to $\mathrm{RC} 1$ and other column specimens, as the stress was 120.5 as well as the strain were 0.0006025 . Moreover, the C-40-20L2 has the second maximum stress and strain, as it was $119.9 \mathrm{~N} / \mathrm{mm}^{2}$ and the strain was 0.0005995 . However, C-40-60L2 has the lowest stress and strain as compared to all other columns because it was about $112.8 \mathrm{~N} / \mathrm{mm}^{2}$ and 0.0005640 . Furthermore, C-40-20L1 has more stress and strain as compared to C-40-60L1, because the stress of C-40-20L1 was $115.3 \mathrm{~N} / \mathrm{mm}^{2}$ and the strain was 0.0005765 and the stress of C-40-60L1 was $108.0 \mathrm{~N} / \mathrm{mm}^{2}$ as well as the strain was 0.0005480 (shown in Graph 20).

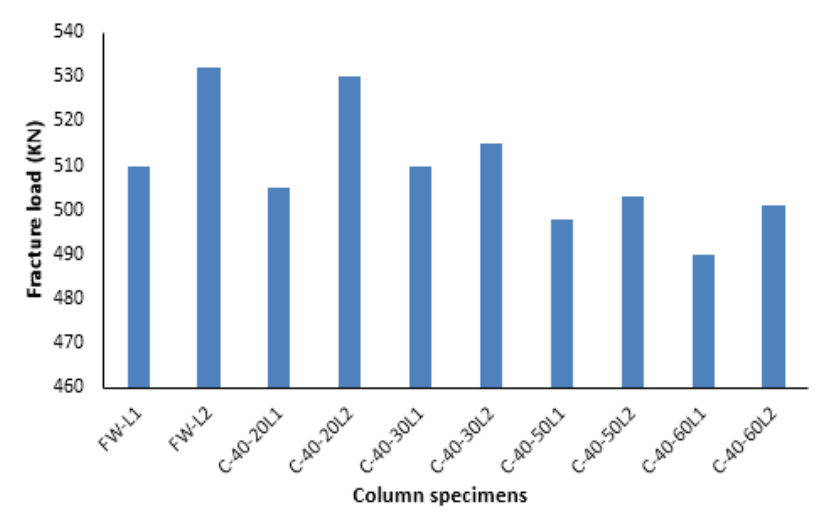

Graph 21. Comparison of fracture load and column specimens

In this graph, It was noticeable that FW-L2 and spacing of 20L2 specimens has a maximum load that was taken at $625 \mathrm{KN}$ and $622 \mathrm{KN}$ after the fracture load of $532 \mathrm{KN}$ and $530 \mathrm{KN}$ as compared to other beam specimens. However, in the specimen spacing of $50 \mathrm{~L} 1$, the load reached to fracture point at $498 \mathrm{KN}$. Then, fewer loads were taken in between fracture load and failure load. It was observed that the specimens which were strengthened by one layer of carbon fiber have experienced a sudden decrease in load after the failure load of the specimen, as shown in Graph 21.

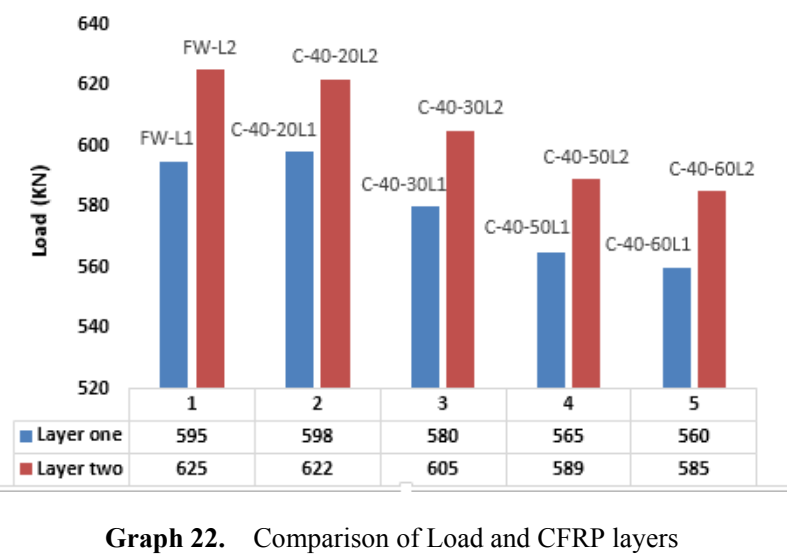

This graph illustrates the load versus CFRP relationship. Although the FW of layer two has a greater load capacity than the FW of layer one its peak load is at $625 \mathrm{KN}$ (Table 
4). But while, the $20 \mathrm{~mm}$ column spacing of carbon fiber layer one has a smaller load ability than the $20 \mathrm{~mm}$ spacing of layer two, although this $20 \mathrm{~mm}$ spacing of the second layer of specimen has a greater load-bearing capacity, as it was load $622 \mathrm{KN}$. Nevertheless, in comparison to other column specimens, CFRP layers one and two with a spacing of $50-60 \mathrm{~mm}$ have less load-bearing capacity, as shown in graph (Graph 22).

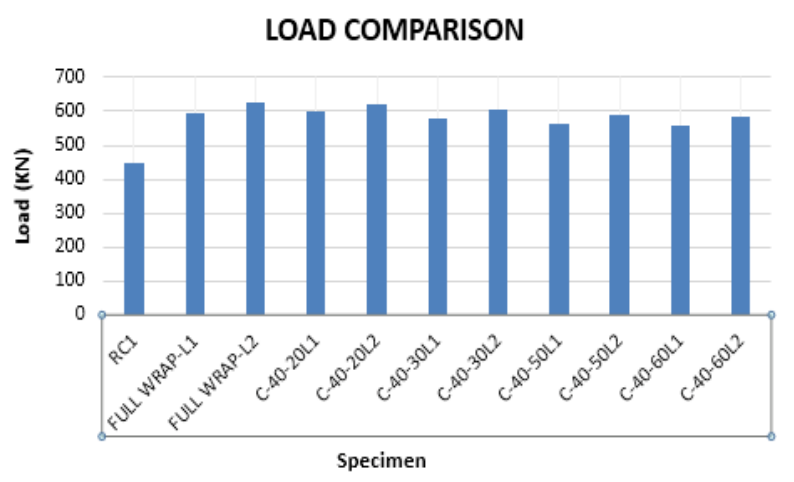

Graph 23. Comparison of Load and column specimens

The load and column specimens were compared in this graph. According to the graph, both C-40-20L2 and a full wrap of layer two have a high capability of load as compared to other column members, as they were $622 \mathrm{KN}$ and $625 \mathrm{KN}$ of load. Apart from these,C-40 30L2, C-40 $20 \mathrm{~L} 1$, and full-wrap-L1 have a nearly similar proportion of load bonded by carbon fiber, but the reference columns do not have enough load-bearing capability to the comparison of all used by carbon fiber columns, as only $432 \mathrm{KN}$, which is shown in (Graph 23)

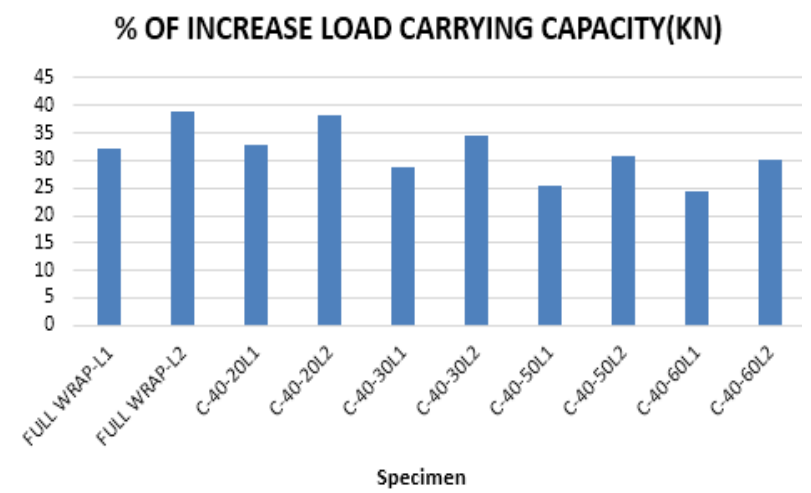

Graph 24. Comparison of \%age load carrying capacity to reference column

The percentage of load-carrying capacity as compared to the reference column is represented in this graph. In comparison to the reference columns, the full-wrap of the second layer has the largest percentage of load-bearing capability, at $38.8 \%$. Furthermore, the C-40-20L2 was the second-best capable of carrying a load, with a percentage of 38.2. Nevertheless, both C-40-60L2 and-40-50L2 have nearly the same percentage of handling a load at 30.0 and
$30.8 \%$, but C-40-60L1 has less ability to carry the load at $24.4 \%$, as shown in (Graph 24).

\section{Conclusions}

\subsection{Flexural Strengthening}

The Partial-U-Wrapping and Full-wrapping methods showed less control in deflection as compared to partial full wrapping.

The percentage of load-carrying capacity of beams PW-L2, CBES-L2, and FW-L2 was enhanced by percent, $27.4 \%, 35.2 \%$, and $36.6 \%$, higher than the reference beam. The full-wrapping beam member has a greater load-carrying capacity than all other beam specimens.

In contrast to the reference beam, the CFST beam members bonded with CFRP were able to sustain a higher ultimate load.

\subsection{Axial Strengthening}

The carbon fiber layers with a smaller spacing have a better axial load-carrying capacity than the carbon fiber layers that have wider spacing.

The percentage of the load-carrying capability of column specimen FW-L2 was $38.8 \%$ higher than the reference column, and this column also sustains the maximum stress-strain.

In comparison to the reference column, the CFST column members bonded with CFRP were able to sustain a greater ultimate load.

\section{REFERENCES}

[1] Shams, Mohammad, and M. AlaSaadeghvaziri. State of the Art of Concrete-Filled Steel Tubular Columns, Structural Journal, Vol. 94, No. 5, pp.558-571, 1997.

[2] Varma, Amit H., James Ricles, Richard Sause, and Le Wu Lu. Experimental Behavior of High Strength Square Concrete Filled Steel Tube (CFT) Columns, Journal of Structural Engineering, Vol. 128, No. 3, pp. 309-318, 2002.

[3] Mursi, Mohanad, and Brian Uy. Strength of Concrete Filled Steel Box Columns Incorporating Interaction Buckling, Journal of Structural Engineering, Vol. 129, No. 5, pp. 626-639, 2003

[4] Liu, Dalin, and Wie Min Gho. Axial load behaviour of high-strength rectangular concrete-filled steel tubular stub columns, Thin-Walled Structures, Vol. 43, No. 8, pp. 1131-1142, 2005.

[5] Gautam, Bishnu Prasad, and Takashi Matsumoto. Failure Mechanism of Empty and Concrete-Filled CFRP Box Beams, Journal of Composites for Construction, Vol. 14, No. 3, pp. $336-345,2010$. 
[6] Kim, Heecheul, Kyoung Hun Lee, Young Hak Lee, and Junbok Lee. Axial behavior of concrete-filled carbon fiber-reinforced polymer composite columns, The Structural Design of Tall and Special Buildings, Vol. 21, No. 3, pp. 178-193, 2012.

[7] Sundarraja, m c, and g ganeshprabhu. Behaviour of cfst members under compression externally reinforced by cfrp composites, journal of civil engineering and Management, Vol. 19, No. 2, pp. 184-195, 2013.

[8] Yu, T., Y. M. Hu, and J. G. Teng. FRP-confined circular concrete-filled steel tubular columns under cyclic axial compression, Journal of Constructional Steel Research, Vol. 94, pp. 33-48, 2014.

[9] Kiruthika, P., S. Balasubramanian, M. C. Sundarraja, and J. Jegan. Strengthening of Concrete Filled Steel Tubular Columns using FRP Composites, International Journal of Innovative Research in Science, Engineering and Technology, Vol. 4, No. 4, 2015.
[10] Alam, MdIftekharul, Sabrina Fawzia, and Xuemei Liu. Effect of bond length on the behaviour of CFRP strengthened concrete-filled steel tubes under transverse impact, Composite Structures, Vol. 132, pp. 898-914, 2015

[11] Shankar, G. R. Vijay, M. C. Sundarraja, Yun Yong Kim, and G. Ganesh Prabhu. Using carbon-fibre-reinforced polymer to strengthen concrete-filled steel tubular columns, Structures and Buildings, Vol. 170, No. 12, pp. 917-927, 2017.

[12] Xu, Na, DujianZou, and Xueyi Fu. Force transmission mechanism of a new joint of concrete-filled rectangular steel tubular column under axial compression, International Journal of Distributed Sensor Networks, Vol. 14, No. 8, 2018

[13] Balamurugan G., and T. S. Viswanathan. "Evaluation of the Effects of Orientation and Coverage Areas of FRP Lamination Bonded with Two-Way RC Slabs-A Modular Approach", Civil Engineering and Architecture, Vol. 8, No. 4, pp. 706-713, 2020. DOI: 10.13189/cea.2020.080432 